\title{
A FORMAÇÃO DO ADMINISTRADOR NA PERSPECTIVA DAS COMPETÊNCIAS INDIVIDUAIS REQUERIDAS
}

\author{
THE ADMINISTRATOR FORMATION IN PERSPECTIVE OF INDIVIDUAL COMPETENCIES \\ REQUIRED
}

\author{
Donizeti Leandro de Souza \\ souza.doni@yahoo.com.br \\ Universidade Federal de Lavras - Lavras - MG - Brasil \\ Jorgiane Suelen de Sousa \\ jsuelenpatos@yahoo.com.br \\ Universidade Federal de Lavras - Lavras - MG - Brasil
}

\section{Robert Delano de Souza Corrêa}

robdelan@yahoo.com.br

Universidade Federal de Lavras - Lavras - MG - Brasil

\section{André Luiz Zambalde}

zamba@dcc.ufla.br

Universidade Federal de Lavras - Lavras - MG - Brasil

\section{Resumo}

Este estudo tem como objetivo avaliar se as práticas das Instituições de Ensino Superior (IES) têm sido alinhadas às competências demandadas pela literatura, além de investigar quais variáveis demográficas podem interferir no desenvolvimento das mesmas. Foi realizada uma pesquisa quantitativa, por meio de técnicas estatísticas descritivas e multivariadas em três IES privadas de Minas Gerais, tendo como referência, o conjunto das competências individuais requeridas propostas por Sant'Anna (2002). Os resultados demonstram que as IES pesquisadas têm desenvolvido as competências requeridas em um nível satisfatório, apesar de identificar limitações no desenvolvimento de competências empreendedoras, surgindo a necessidade de se criar ambientes acadêmicos que estimulem a criatividade e a formação empreendedora. 0 estudo pode ser útil para questionar o conceito de competências como algo que transcende a perspectiva organizacional, resgatando a importância da academia no desenvolvimento de uma formação sistêmica de indivíduos talentosos e competentes.

Palavras-chave: Competências requeridas. Formação acadêmica. Cursos de Administração.

\section{ABSTRACT}

This study aims to evaluate whether the practices of higher education institutions (HEIs) have been aligned with the competencies demanded by the literature and which demographic variables may interfere in their development. Was performed a quantitative research using 


\section{Donizeti Leandro de Souza, Jorgiane Suelen de Sousa, Robert Delano de Souza Corrêa e \\ André Luiz Zambalde}

descriptive statistics and multivariate techniques in three private HEIs of Minas Gerais, having with reference, the individual required competencies proposed by Sant'Anna (2002).

The results demonstrate that HEIs surveyed have developed the required competencies at a satisfactory level, despite identifying limitations in the development of entrepreneurial competencies, resulting in the need to create academic environments that foster creativity and entrepreneurial formation. The study may be useful to question the concept of competence as something that transcends organizational perspective, rescuing the importance of academia in the development of a systemic formation of talented and competent individuals.

Keywords: Competencies Required. Education. Administration courses.

\section{INTRODUÇÃO}

Nos últimos anos, os estudos envolvendo o construto "competência" têm despertado a atenção de estudiosos em duas importantes correntes de pensamento: a abordagem americana e a abordagem francesa, em estudos que tratam as competências desde uma concepção comportamentalista a uma perspectiva social. Dessas perspectivas, surgiram na pauta das discussões acadêmicas e empresariais, diferentes instâncias de compreensão sobre o papel das instituições de ensino superior (IES) na formação de competências centrais (LIMA; ROCHA, 2012; SANT'ANNA, 2002; FLEURY; FLEURY, 2001).

Percebe-se que este crescente interesse de estudo tem se formado a partir de demandas cada vez mais desafiadoras, em que a mobilização de novos conhecimentos, habilidades e aptidões transcendem as competências técnicas tradicionais. Desta abordagem tem emergido, para o centro das discussões, o interesse em investigar quais competências centrais são requeridas para uma formação plena, capaz de preparar os indivíduos para os desafios da sociedade (COMINI; KONUMA; SANTOS, 2008; RYCHEN; SALGANIK, 2005).

Com o propósito de ampliar o entendimento acerca das relações entre os construtos: "competências individuais requeridas" e "modernidade organizacional", Sant'Anna (2002) investigou até que ponto a demanda pelas competências requeridas tem sido acompanhada por uma modernidade de políticas e práticas de gestão favorável ao desenvolvimento das mesmas, sendo constatado que o conjunto das competências requeridas não tem sido acompanhado, na mesma proporção, por políticas e práticas de gestão necessárias ao seu desenvolvimento.

Deste debate, outras questões têm-nos instigado a elaborar este artigo. As competências requeridas pelo mercado, além de não alinhadas às práticas organizacionais, têm sido desenvolvidas e alinhadas às práticas educacionais? Qual tem sido o papel das instituições de ensino superior, em especial, dos cursos de Bacharelado em Administração no desenvolvimento de tais competências? Estas questões se mostram relevantes, pois resgatam o papel da academia em formar profissionais capacitados, capazes de enfrentar os diversos desafios da atual sociedade do conhecimento.

Assim, o objetivo deste estudo é avaliar se as práticas das IES têm sido alinhadas às competências individuais requeridas propostas por Sant'Anna (2002), buscando investigar quais competências têm sido mais e/ou menos desenvolvidas nos cursos de Administração e quais variáveis demográficas podem interferir no desenvolvimento das mesmas.

\section{FUNDAMENTAÇÃO TEÓRICA}




\section{A FORMAÇÃO DO ADMINISTRADOR NA PERSPECTIVA DAS COMPETÊNCIAS INDIVIDUAIS REQUERIDAS}

A gestão de competências nasceu no campo da Psicologia organizacional imersa em teorias motivacionais, procurando uma explicação para o bom desempenho no trabalho (SANTOS, 2003). Desde então, duas correntes de pensamento têm se destacado na literatura: (1) a abordagem americana que, sob influência do modelo taylorista-fordista, conceitua competência como sendo um conjunto mensurável de conhecimentos, habilidades e atitudes associados ao desempenho de determinado cargo ocupado (LIMA; ROCHA, 2012) e (2) a abordagem francesa que, a partir do questionamento da qualificação técnica defendida pela abordagem americana, passou a ser vista como a mobilização do indivíduo num ambiente organizacional cada vez mais mutável e complexo (FLEURY; FLEURY, 2001).

Em 1973 McClelland iniciou o debate americano sobre competências com a publicação do artigo: Testing for Competence rather than Intelligence. Durante a década de 1980, Richard Boyatzis, reanalisando os dados de estudos sobre as competências gerenciais, identificou um conjunto de características e traços que definem um desempenho superior. Nesta perspectiva, o conceito de competência é pensado como um conjunto de conhecimentos, habilidades e atitudes que justificam um alto desempenho, sendo fundamentados pela inteligência e personalidade das pessoas. Competência passou a ser percebida como um estoque de recursos que os indivíduos devem possuir para assumir determinadas funções (REJAS-MUSLERA; URQUIZA; CEPEDA, 2011; FLEURY; FLEURY, 2001).

A partir da década de 1990, com a configuração de um novo cenário global, surgiu na literatura francesa o conceito de competência transcendendo a visão de qualificação técnica, passando o indivíduo a ser o principal foco das discussões. 0 conceito de competências foi então reconfigurado não apenas como um conjunto de conhecimentos, habilidades e atitudes (abordagem americana), mas sim com suas realizações em determinados contextos. 0 foco passou a ser a ação e mobilização das capacidades técnicas, cognitivas e psicossociais dos indivíduos no ambiente de trabalho (LIMA; ROCHA, 2012).

0 debate francês nasceu como um questionamento ao conceito americano de competências (associado aos cargos), centrando os estudos no prolongamento direto da competência que o indivíduo mobiliza em face de uma situação profissional cada vez mais mutável e complexa (FLEURY; FLEURY, 2001). Assim, competências deixaram de ser apenas a aquisição de conhecimentos, habilidades e atitudes, passando a envolver a capacidade de atender às demandas complexas do mercado, mobilizando recursos psicossociais (incluindo habilidades e atitudes) em contextos particulares, de forma sistêmica e muitas vezes imprevista (RYCHEN; SALGANIK, 2005; ZARIFIAN, 2003).

Frente a este embate de conceitos, percebe-se que o construto "competência" assume abordagens epistemológicas, teóricas e morfológicas ainda em construção, pois não existe um consenso sobre seu conceito.

Fleury e Fleury (2001) asseveram que é possível encontrar na literatura americana e francesa definições para competências essenciais, organizacionais e individuais, demandando a construção de modelos teóricos que explicitem como esses diferentes conceitos se articulam e podem contribuir para o entendimento de propostas de desenvolvimento pessoal e/ou organizacional.

Já Sáiz (2011) apresenta alguns problemas teórico-metodológicos identificados em estudos sobre competências, destacando os principais desafios em quatro principais abordagens: base 


\section{Donizeti Leandro de Souza, Jorgiane Suelen de Sousa, Robert Delano de Souza Corrêa e \\ André Luiz Zambalde}

teórica empírica; diversidade de conceitos; uso de técnicas e contextos ambientais em que são empregados, conforme apresentado no Quadro 1.

\begin{tabular}{|l|l|}
\hline Principais problemas & Aspectos chave \\
\hline Base teórico-empírica & Escassa fundamentação de enfoque e aplicação (indefinição de modelos). \\
\hline Conceitos de competência & Excesso de termos, muitos deles redundantes ou inadequados. \\
\hline Técnicas empregadas & Uso inadequado ou impróprio das técnicas disponíveis. \\
\hline Contextos de aplicação & Fatores condicionantes que favorecem o desenvolvimento de vários \\
\hline
\end{tabular}

Quadro 1 - Principais problemas relacionados a gestão de competências e sua aplicação

Fonte: Sáiz (2011)

Tais abordagens indicam que o campo de estudo sobre competências tem assumido diversos desafios para um alinhamento teórico-metodológico adequado, deixando porosidades tanto no campo teórico como prático, remetendo o pesquisador a desafios teóricos e os profissionais ao equacionamento da ambiguidade gerada entre o discurso e a prática (LIMA; ROCHA, 2012; MARTÍNEZ; CARMONA, 2009; SANTOS, 2003).

\section{Conceituando competências}

Frente às atuais transformações do mundo de negócios, as organizações têm necessitado de indivíduos talentosos e competentes para acompanhar um ambiente cada vez mais complexo e exigente. Muitos estudiosos e especialistas concordam que lidar com os desafios de hoje requer um melhor desenvolvimento de habilidades individuais que vão muito além da básica reprodução do conhecimento acumulado. Competências envolvem a mobilização de aptidões cognitivas e práticas, habilidades criativas e outros recursos psicossociais, tais como atitudes, motivação e valores (RYCHEN; SALGANIK, 2005).

O conceito de competência valoriza a capacidade de combinar e mobilizar, adequadamente, recursos já desenvolvidos, num contexto marcado pela baixa previsibilidade de negócios, ampliação da concorrência, foco nos resultados e na alta aprendizagem. Não deve ser algo estático e limitado à criação de um conhecimento específico, mas sim um processo contextualizado e reconhecido de trocas com o ambiente (RUAS; ANTONELLO; BOFF, 2005). Competências representam a soma do aprendizado de todo o conjunto de habilidades, conhecimentos, know-how tecnológico e resultados dos processos decisórios da organização, constituindo uma fonte de vantagem competitiva porque deve ser única (UBEDA; SANTOS, 2008; FLEURY; FLEURY, 2001).

Segundo Blas (2007), na literatura é possível encontrar a existência de pelo menos quatro abordagens de competências: (1) funcionais: competências são derivadas de funções; (2) comportamentais: competências são derivadas de comportamentos de sucesso; (3) construtivistas: competências são derivadas de um processo de discussão e debate e (4) holísticas: competências envolvem a integração de todas as habilidades necessárias.

Os modelos funcionais e comportamentais seguem a epistemologia americana, em que o foco dos estudos está centrado nas qualificações necessárias aos cargos, visando um desempenho superior (BOYATZIS, 1982; MCCLELLAND, 1973). O modelo construtivista segue a epistemologia francesa, pois competência passa a representar o conjunto de aprendizagens sociais e comunicacionais do indivíduo em práticas sociais. Mais importante do que "estocar" conhecimentos, habilidade e atitudes é preciso saber utilizá-los em contextos particulares 


\section{A FORMAÇÃO DO ADMINISTRADOR NA PERSPECTIVA DAS COMPETÊNCIAS INDIVIDUAIS REQUERIDAS}

(ZARIFIAN, 2003; PERRENOUD, 2001; LE BOTERF, 1994).

Por fim, o modelo holístico assume bases epistemológicas mais sistêmicas, pois competências são definidas como um conjunto de habilidades-chave necessárias ao bom funcionamento da sociedade, transcendendo a perspectiva organizacional ao identificar a formação de indivíduos em relações de valores compartilhados para fins econômicos e sociais (UBEDA; SANTOS, 2008; RYCHEN; SALGANIK, 2005; SANT'ANNA, 2002; FLEURY; FLEURY, 2001).

Para estabelecer um quadro de competências adequado, torna-se preciso desenvolver nos indivíduos a necessidade para pensar e agir reflexivamente, envolvendo não apenas a capacidade de aplicar rotineiramente uma fórmula ou método para enfrentar uma situação, mas também a capacidade de lidar com as mudanças, aprender com a experiência e agir com uma postura crítica. Reflexividade, assim, implicaria o uso de habilidades metacognitivas (pensar sobre o pensar), não apenas sobre como os indivíduos pensam, mas também sobre como eles constroem uma experiência global, incluindo os seus pensamentos, sentimentos e relações sociais (RYCHEN; SALGANIK, 2005).

\section{Novas perspectivas sobre as competências profissionais requeridas}

Para atender à nova demanda global por profissionais mais preparados para os desafios da atualidade, novas competências têm sido exigidas (MARTÍNEZ; CARMONA, 2009). Neste sentido, Sant'Anna (2002), com o propósito de ampliar o entendimento acerca das relações entre os construtos "competências individuais requeridas" e "modernidade organizacional", investigou até que ponto a demanda pelas competências requeridas tem sido acompanhada por uma modernidade de políticas e práticas de gestão capazes de propiciar um ambiente organizacional favorável ao desenvolvimento das mesmas.

Através de uma extensa revisão bibliográfica em autores da abordagem americana e francesa, Sant'Anna (2002) identificou 15 (quinze) competências profissionais centrais, as quais foram denominadas de "competências individuais requeridas", são elas: (1) domínio de novos conhecimentos técnicos associados ao cargo ou função; (2) capacidade de aprender novos conceitos e tecnologias; (3) criatividade; (4) capacidade de inovação; (5) capacidade de comunicação; (6) capacidade de relacionamento interpessoal; (7) capacidade de trabalho em equipe; (8) autocontrole emocional; (9) visão de mundo ampla e global; (10) capacidade de lidar com situações novas e inusitadas; (11) capacidade de lidar com incertezas e dúvidas; (12) iniciativa de ação e decisão; (13) capacidade de comprometer-se com os objetivos da organização; (14) capacidade de gerar resultados efetivos e (15) capacidade empreendedora.

Segundo o autor, novos requisitos estão sendo exigidos dos indivíduos. Habilidades cognitivas e características comportamentais estão sendo valorizadas no ambiente de trabalho como competências importantes para lidar com a imprevisibilidade do ambiente, exigindo uma modernidade organizacional por meio de estruturas, estratégias, políticas e práticas de gestão que favoreçam a formação de conteúdos culturais capazes de estimular um comportamento competente. Porém, o autor identifica, por meio de um estudo empírico com alunos de graduação e pós-graduação (lato sensu), que a demanda pelas competências requeridas não tem sido acompanhada, em mesmo nível, por uma modernidade de políticas e práticas de gestão, sugerindo a necessidade de ambientes organizacionais mais aderentes aos novos perfis profissionais requeridos (SANT'ANNA, 2002). 
Deste debate, outra questão pode ser evidenciada: "as competências requeridas pelo mercado, além de não alinhadas às práticas organizacionais, têm sido desenvolvidas e alinhadas às práticas educacionais?" Esta questão se mostra relevante, pois, diante dos atuais desafios da sociedade, também é papel da educação agir como ferramenta de construção de um ideal humano voltado à aquisição de competências (MARTÍNEZ; CARMONA, 2009).

O atual cenário econômico, político e social tem imposto demandas mais desafiadoras sobre os indivíduos que são confrontados com a complexidade de exigências, ao longo da vida, para o desenvolvimento de competências-chave. Esta complexidade, mutável e conflituosa coloca os objetivos e as estratégias para atingir metas de educação no centro do debate sobre uma reforma educacional ampla (RYCHEN; SALGANIK, 2005; OECD, 2001).

De fato, medir a qualidade dos resultados da educação, estimar o retorno econômico e social para a aprendizagem e identificar fatores determinantes para o sucesso educativo é um tópico de discussão em curso que estimula grande interesse em todo o mundo (OECD, 2001). Definir essas competências pode melhorar as avaliações de quão bem preparados os jovens e adultos são para os desafios da vida, bem como identificar as metas globais para os sistemas de educação e aprendizagem (RYCHEN; SALGANIK, 2005).

O conceito de currículo por competência tem emergido discussões e proposições como um novo paradigma normativo às políticas internacionais de educação, envolvendo instâncias governamentais, gestores dos sistemas de educação, pesquisadores, educadores e políticos com a finalidade de encontrar uma direção compartilhada e dar os referenciais para os sistemas de educação em um mundo convulsionado pela economia, pela política e pela tecnologia. Este ambicioso propósito mantém a expectativa de que a escola assuma seu papel central de oferecer uma base sólida de conhecimentos que permita aos estudantes desenvolver competênciaschave para sua formação, a fim de que possam enfrentar as transformações emergentes da sociedade (CHIZZOTTI; CASALI, 2012; RYCHEN; SALGANIK, 2005).

\section{Aspectos metodológicos}

Como procedimentos metodológicos, a pesquisa assume uma abordagem descritiva e quantitativa, partindo de uma amostra não probabilística (VERGARA, 2006) composta por alunos de 3 (três) IES privadas situadas na região do Triângulo Mineiro/Alto Paranaíba e no Sul de Minas Gerais. 0 estudo envolveu apenas os discentes concluintes dos cursos de Bacharelado em Administração para avaliar em que medida as competências requeridas têm sido desenvolvidas durante o período de formação acadêmica.

O levantamento de dados consistiu na aplicação de questionários estruturados em duas seções básicas: a seção I, composta por questões demográficas (sexo, faixa etária, estado civil, experiência profissional) e a seção II composta por questões preditoras adaptadas de Sant'Anna (2002), contemplando as "competências individuais requeridas", sendo estas, questões assertivas distribuídas em uma escala intervalar de 0 a 10.

Com o propósito de verificar os possíveis problemas de compreensão, duração e sequência das questões, foram aplicados, no primeiro semestre de 2013, 45 questionários como etapa de préteste, sendo realizados alguns ajustes nas estruturas das questões e nas técnicas de coletas, 


\section{A FORMAÇÃO DO ADMINISTRADOR NA PERSPECTIVA DAS COMPETÊNCIAS INDIVIDUAIS REQUERIDAS}

visando maior esclarecimento e confiabilidade nos dados coletados. Definida as estratégias de pesquisa e os ajustes necessários, foram aplicados 172 questionários, dos quais se obteve uma amostra final de 157 questionários preenchidos.

Ademais, cabe ressaltar que os dados foram tratados por técnicas estatísticas descritivas (distribuição de frequência, média, crosstabs) e técnicas multivariadas (análise fatorial, análise de clusters e análise discriminante), tendo como propósito triangular diferentes métodos para identificar características específicas dos participantes. 0 tratamento dos dados foi realizado pelo pacote estatístico SPSS ${ }^{\circledR}$ (Statistical Package for the Social Sciences).

\section{Resultados e discussão}

Em relação ao perfil demográfico dos respondentes, observou-se que a maioria são estudantes do sexo feminino (66,9\%), solteiros (78,3\%) e com idade até 25 anos $(72,6 \%)$. Quanto ao perfil profissional, observou-se que os principais motivos que levaram os alunos a ingressarem no curso de Administração foram a possibilidade de ascensão profissional e o interesse pela área administrativa, representando, estes, aproximadamente $69 \%$ dos respondentes. Percebeu-se, ainda, uma alta taxa de respondentes aos quais afirmaram ingressar no curso de Administração por indecisão profissional ou falta de opção, representando, aproximadamente, $25 \%$ dos respondentes, outros fatores corresponderam a cerca de $6,0 \%$.

Questionados sobre a atuação na área administrativa, 13,4\% dos entrevistados afirmaram nunca trabalhar na área; $14,6 \%$ já trabalharam na área, mas no momento da pesquisa não estavam atuando e $72 \%$ afirmaram estarem trabalhando no período da pesquisa. Dentre as áreas de atuação, o setor de serviços foi o mais citado pelos respondentes (41,2\%), seguido pelo comércio $(32,4 \%)$, indústria $(17,6 \%)$ e setor público $(8,8 \%)$. Em relação ao porte das empresas, foi observado que a maioria atua/atuou em grandes empresas $(50,7 \%)$, seguido por micro e pequenas empresas $(46,3 \%)$ e serviço autônomo $(2,9 \%)$.

Por fim, questionados sobre a realização de estágio, a maioria dos entrevistados $(31,8 \%)$ afirmou que ainda não realizaram estágio na área, apesar de cursarem o último ano da graduação; 28\% afirmaram ter realizado apenas um estágio (curricular ou extracurricular); $25,5 \%$ afirmaram estar realizando o estágio no momento da pesquisa e 14,7\% afirmaram já terem realizado estágio em várias empresas.

\section{Desenvolvimento das competências requeridas}

A segunda parte do questionário teve como propósito avaliar, na percepção dos alunos, o desenvolvimento das competências individuais requeridas proposta por Sant'Anna (2002), sendo os resultados apresentados na Tabela 1.

\begin{tabular}{lll}
\hline Competências individuais requeridas & Média & Desvio padrão \\
\hline Capacidade de lidar com incertezas e dúvidas & 7,16 & 1,57 \\
\hline Criatividade & 7,23 & 1,82 \\
\hline Capacidade de aprender e aplicar novos conceitos e tecnologias & 7,35 & 1,66 \\
\hline Capacidade empreendedora & 7,47 & 2,01 \\
\hline Capacidade de inovação & 7,56 & 1,71 \\
\hline Capacidade de lidar com situações novas e inusitadas & 7,58 & 1,74 \\
\hline Autocontrole emocional & 7,59 & 1,82 \\
\hline Domínio de novos conhecimentos técnicos ligados a administração & 7,72 & 1,64 \\
\hline Iniciativa de ação e decisão & 7,80 & 1,68 \\
\hline
\end{tabular}




\begin{tabular}{lll} 
Visão de mundo ampla e global & 7,83 & 1,60 \\
\hline Capacidade de gerar resultados efetivos em grupo & 7,90 & 1,56 \\
\hline Capacidade de comunicação e uso da linguagem escrita e falada & 7,93 & 1,67 \\
\hline Capacidade de trabalhar em equipes & 8,10 & 1,84 \\
\hline Capacidade de relacionamento interpessoal & 8,15 & 1,47 \\
\hline Capacidade de comprometimento e responsabilidade & 8,54 & 1,54 \\
\hline Índice de Competências Desenvolvidas - ICD & $\mathbf{7 , 7 3}$ & \\
\hline
\end{tabular}

Tabela 1: Valores médios sobre o desenvolvimento de competências requeridas.

Fonte: Dados da pesquisa

Nota-se, pela Tabela 1, que a competência menos percebida foi a "capacidade de lidar com incertezas e dúvidas" e a competência mais desenvolvida refere-se a "capacidade de comprometimento e responsabilidade". A média geral das competências requeridas apresentou um escore médio de 7,73, valor este considerado satisfatório, uma vez que se encontra alinhado ao Índice das Competências Requeridas (SANT'ANNA, 2002), evidenciando que as competências desenvolvidas nas IES pesquisadas, têm acompanhado o conjunto das competências requeridas pelo mercado.

Com o propósito de testar a dimensionalidade das escalas, procedeu-se a análise fatorial com o propósito de reduzir as 15 competências analisadas em fatores latentes capazes de manter a unidimensionalidade das medidas. Segundo Hair et al. (2009) a análise fatorial é uma técnica de interdependência, cujo propósito principal é definir a estrutura de correlação entre variáveis, definindo conjuntos de variáveis que são fortemente interrelacionadas, conhecidos como fatores, possibilitando, assim, a simplificação das informações ao agrupar as variáveis segundo as relações de correlação que estas possuem entre si.

Para obtenção dos fatores foi utilizado o método dos componentes principais, considerando a variância total dos dados na extração de 3 (três) fatores principais, número considerado mais adequado para classificar os grupos de variáveis. Visando facilitar a interpretação dos fatores principais, optou-se por utilizar a função de Matriz rotacionada, através do método Varimax com normalização Kaiser, cujo objetivo é aumentar a discriminação entre os fatores, no sentido de que cada variável sofra maior influência de determinado fator e menor influência de outro, facilitando assim o agrupamento (FÁVERO et al., 2009; HAIR et al., 2009). Ademais, com o propósito de considerar apenas as cargas fatoriais mais relevantes para os agrupamentos, foi considerada uma carga fatorial igual ou superior a 0,500 .

Os resultados apresentaram um coeficiente de Kaiser-Meier-Olkin (KMO) de 0,905 e teste de esfericidade de Bartlett significativo a 1\%, representando uma excelente adequação da amostra (HAIR et. al., 2009). Com base em Sant'Anna (2002), verificou-se que 94,3\% das correlações calculadas, não inclusos os valores na diagonal da matriz, mostraram-se iguais ou superiores a 0,300 , sendo significativos ao nível de $1 \%$ pelo coeficiente de Pearson, indicando que os dados seguem a premissa de linearidade.

Em relação aos níveis de comunalidade (grau em que os itens da escala encontram-se associados à combinação linear gerada pelos fatores extraídos), os resultados apontaram a presença de indicadores relevantes, variando de 0,518 (capacidade de lidar com incertezas e dúvidas) a 0,812 (capacidade de inovação).

Por fim, cabe ressaltar que os três fatores gerados correspondem a $64,5 \%$ da variância total observada, número considerado satisfatório, uma vez que Malhotra (2006) recomenda que os fatores extraídos respondam por, no mínimo, $60 \%$ da variância. Além disso, os testes das 


\section{A FORMAÇÃO DO ADMINISTRADOR NA PERSPECTIVA DAS COMPETÊNCIAS INDIVIDUAIS REQUERIDAS}

consistências internas apresentaram um coeficiente Alpha de Cronbach superior a 0,70 em todos os agrupamentos, valor considerado adequado, segundo Hair Jr et al. (2009).

No grupo 1, foram agrupadas 6 (seis) variáveis: capacidade de gerar resultados efetivos em grupo, capacidade de lidar com situações novas e inusitadas, capacidade de trabalhar em equipe, iniciativa de ação e decisão, autocontrole emocional e capacidade de relacionamento interpessoal. 0 agrupamento dessas variáveis permite interpretar este fator de "competências interpessoais", indicando a capacidade dos indivíduos interagirem com outras pessoas, trabalhar em equipe, lidar com conflitos e gerar resultados efetivos nas diversas situações e/ou pressões de trabalho (GODOY; ANTONELLO, 2009; RYCHEN; SALGANIK, 2005).

Já no grupo 2, foram agrupadas 5 (cinco) variáveis: domínio de conhecimentos técnicos ligados a administração, capacidade de inovação, capacidade empreendedora, capacidade de lidar com incertezas e dúvidas e criatividade. 0 agrupamento dessas variáveis permite interpretar esse fator "competências empreendedoras", indicando a capacidade dos indivíduos serem inovadores, criativos, dominarem conhecimentos técnicos relacionados à profissão e tomarem decisões frente às incertezas e dúvidas (ZUAZO, 2010).

Por fim, no grupo 3 foram agrupadas 4 (quatro) variáveis: capacidade de comprometimento e responsabilidade, visão de mundo ampla e global, capacidade de comunicação e uso da linguagem escrita e falada e capacidade de aprender e aplicar novos conceitos e tecnologias. 0 agrupamento dessas variáveis permite interpretar esse fator de "competências sistêmicas", indicando as competências necessárias para a interação social dos indivíduos por meio da capacidade de comunicação, comprometimento e responsabilidade, sendo estes, requisitos essenciais para novos aprendizados (GODOY; ANTONELLO, 2009; RYCHEN; SALGANIK, 2005). Os resultados do agrupamento são apresentados no Quadro 2.

\begin{tabular}{|c|c|c|}
\hline $\begin{array}{c}\text { GRUPO 1: } \\
\text { Competências interpessoais }\end{array}$ & $\begin{array}{l}\text { GRUPO 2: Competências } \\
\text { empreendedoras }\end{array}$ & $\begin{array}{c}\text { GRUPO 3: } \\
\text { Competências sistêmicas }\end{array}$ \\
\hline $\begin{array}{l}\text { Gerar resultados efetivos em } \\
\text { grupo }\end{array}$ & $\begin{array}{l}\text { Domínio de conhecimentos } \\
\text { técnicos ligados a administração }\end{array}$ & $\begin{array}{l}\text { Capacidade de comprometimento e } \\
\text { responsabilidade }\end{array}$ \\
\hline $\begin{array}{l}\text { Lidar com situações novas e } \\
\text { inusitadas }\end{array}$ & Capacidade de inovação & Visão de mundo ampla e global \\
\hline Trabalhar em equipes & Capacidade empreendedora & $\begin{array}{l}\text { Capacidade de comunicação e uso da } \\
\text { linguagem escrita e falada }\end{array}$ \\
\hline Iniciativa de ação e decisão & $\begin{array}{l}\text { Capacidade de lidar com } \\
\text { incertezas e dúvidas }\end{array}$ & $\begin{array}{l}\text { Capacidade de aprender e aplicar } \\
\text { novos conceitos e tecnologias }\end{array}$ \\
\hline Autocontrole emocional & Criatividade & \\
\hline Relacionamento interpessoal & & \\
\hline Alpha de Cronbach 0,86 & Alpha de Cronbach 0,87 & Alpha de Cronbach 0,78 \\
\hline
\end{tabular}

Quadro 2: Agrupamentos das competências requeridas.

Fonte: Dados da pesquisa 
Uma vez agrupado, o conjunto das competências requeridas em fatores latentes, procedeu-se à análise do desenvolvimento das mesmas através dos valores médios, conforme apresentado na Tabela 2:

\begin{tabular}{llll}
\cline { 2 - 3 } & $\begin{array}{l}\text { GRUPO 1: } \\
\text { Competências } \\
\text { interpessoais }\end{array}$ & $\begin{array}{l}\text { GRUPO 2: } \\
\text { Competências empreendedoras }\end{array}$ & $\begin{array}{l}\text { GRUPO 3: } \\
\text { Competências } \\
\text { sistêmicas }\end{array}$ \\
\hline ICD & 7,85 & 7,43 & 7,91 \\
\hline
\end{tabular}

Tabela 2: Agrupamento das competências requeridas em fatores

Fonte: Dados da pesquisa

Pelos resultados, percebe-se que os conjuntos das "competências sistêmicas" e "competências interpessoais" têm sido bem desenvolvidos no ambiente acadêmico, representando um ICD = 7,91 e 7,85, respectivamente, acima do ICR de 7,80 calculado por Sant'Anna (2002). Já o grupo de competências menos desenvolvido tem sido as "competências empreendedoras", principalmente nas competências que envolvem o estímulo a criatividade e a inovação, atingindo um ICD de 7,43, valor abaixo do ICR de 7,80.

Com o intuito de tratar os dados disponíveis de forma mais aprofundada, utilizou-se a análise de clusters hierárquicos para realizar o agrupamento dos respondentes. Na pesquisa, empregou-se o método de Ward e a medida de similaridade da distância euclidiana ao quadrado, sendo extraídos três agrupamentos denominados, respectivamente, como G1 "menos satisfeitos" (49 respondentes), G2 "satisfeitos" (81 respondentes) e G3 “muito satisfeitos" (27 respondentes). A partir destes grupos foi utilizada a técnica descritiva crosstabs para cruzar o perfil dos respondentes com o desenvolvimento das competências requeridas, sendo apresentadas no Quadro 3 apenas as variações mais relevantes.

\begin{tabular}{|c|c|c|c|}
\hline Especificação & $\begin{array}{c}\text { GRUPO l- } \\
\text { MAIS INSATISFEITOS }\end{array}$ & $\begin{array}{c}\text { GRUPO 2- } \\
\text { SATISFEITOS }\end{array}$ & $\begin{array}{c}\text { GRUPO 3 - } \\
\text { MUITO SATISFEITOS }\end{array}$ \\
\hline $\begin{array}{l}\text { Total de } \\
\text { pessoas }\end{array}$ & $49(31,21 \%)$ & $81(51,59 \%)$ & $27(17,20 \%)$ \\
\hline Sexo & $\begin{array}{l}\text { Masculino }(40,8 \%) \\
\text { Feminino }(59,2 \%)\end{array}$ & $\begin{array}{l}\text { Masculino }(34,6 \%) \\
\text { Feminino }(65,4 \%)\end{array}$ & $\begin{array}{l}\text { Masculino }(14,8 \%) \\
\text { Feminino }(85,2 \%)\end{array}$ \\
\hline $\begin{array}{c}\text { Motivação } \\
\text { para matrícula }\end{array}$ & $\begin{array}{l}\text { Interesse pessoal }(26,5 \%) \\
\text { Ascensão profissional }(32,7 \%) \\
\text { Mudar de profissão }(4,1 \%) \\
\text { Falta de opção }(10,2 \%) \\
\text { Indecisão na carreira }(22,4 \%) \\
\text { Outro (a) }(4,1 \%) \\
\end{array}$ & $\begin{array}{l}\text { Interesse pessoal }(29,6 \%) \\
\text { Ascensão profissional }(37 \%) \\
\text { Mudar de profissão }(7,4 \%) \\
\text { Falta de opção }(8,6 \%) \\
\text { Indecisão na carreira }(17,3 \%) \\
\text { Outro (a) }(0 \%)\end{array}$ & $\begin{array}{l}\text { Interesse pessoal }(44,4 \%) \\
\text { Ascensão profissional }(48,2 \%) \\
\text { Mudar de profissão }(0 \%) \\
\text { Falta de opção }(3,7 \%) \\
\text { Indecisão na carreira }(3,7 \%) \\
\text { Outro (a): } 00(0 \%)\end{array}$ \\
\hline $\begin{array}{l}\text { Experiência } \\
\text { profissional }\end{array}$ & $\begin{array}{l}\text { Não trabalhou na área }(22,4 \%) \\
\text { Já trabalhou, mas no momento } \\
\text { não está atuando }(14,3 \%) \\
\text { Atua há menos de } 1 \text { ano }(12,2 \%) \\
\text { Atua de } 1 \text { a } 3 \text { anos }(22,4 \%) \\
\text { Atua há mais de } 3 \text { anos }(28,6 \%)\end{array}$ & $\begin{array}{l}\text { Não trabalhou na área }(8,6 \%) \\
\text { Já trabalhou, mas no momento } \\
\text { não está atuando }(16 \%) \\
\text { Atua há menos de } 1 \text { ano }(12,3 \%) \\
\text { Atua de } 1 \text { a } 3 \text { anos }(37 \%) \\
\text { Atua há mais de } 3 \text { anos }(26 \%)\end{array}$ & $\begin{array}{l}\text { Não trabalhou na área }(11,1 \%) \\
\text { Já trabalhou, mas no momento } \\
\text { não está atuando }(11,1 \%) \\
\text { Atua há menos de } 1 \text { ano }(14,8 \%) \\
\text { Atua de } 1 \text { a } 3 \text { anos }(29,6 \%) \\
\text { Atua há mais de } 3 \text { anos }(33,3 \%)\end{array}$ \\
\hline Estágio & $\begin{array}{l}\text { Não estagiou na área }(38,8 \%) \\
\text { Esta realizando o primeiro } \\
\text { estágio no momento }(14,3 \%) \\
\text { Realizou apenas o estágio } \\
\text { curricular (obrigatório) }(10,2 \%) \\
\text { Realizou apenas o estágio (não } \\
\text { obrigatório) }(16,3 \%) \\
\text { Estagiou em várias empresas } \\
(20,4 \%)\end{array}$ & $\begin{array}{l}\text { Não estagiou na área }(32,1 \%) \\
\text { Esta realizando o primeiro estágio } \\
\text { no momento }(27,2 \%) \\
\text { Realizou apenas o estágio } \\
\text { curricular (obrigatório) }(16 \%) \\
\text { Realizou apenas o estágio (não } \\
\text { obrigatório) }(13,6 \%) \\
\text { Estagiou em várias empresas } \\
(11,1 \%)\end{array}$ & $\begin{array}{l}\text { Não estagiou na área }(18,5 \%) \\
\text { Esta realizando o primeiro estágio } \\
\text { no momento }(40,7 \%) \\
\text { Realizou apenas o estágio } \\
\text { curricular (obrigatório) }(16,3 \%) \\
\text { Realizou apenas o estágio (não } \\
\text { obrigatório): } 03(11,1 \%) \\
\text { Estagiou em várias empresas } \\
(14,8 \%)\end{array}$ \\
\hline
\end{tabular}




\section{A FORMAÇÃO DO ADMINISTRADOR NA PERSPECTIVA DAS COMPETÊNCIAS INDIVIDUAIS REQUERIDAS}

Quadro 3: Perfil dos grupos compostos pela análise de clusters

Fonte: Dados da pesquisa

Em relação à composição dos agrupamentos, observa-se no grupo "muito satisfeitos" uma diferença significativa na variável sexo, em que apenas 14,8\% dos respondentes eram do sexo masculino. Outra variável de destaque refere-se à motivação pelo curso de Administração, pois no grupo dos "muito satisfeitos" a porcentagem das motivações relacionadas ao interesse pessoal e ascensão profissional foram superiores aos demais grupos, ao passo que a indecisão sobre a carreira foi menor, indicando que a motivação interna dos discentes pela profissão interfere, positivamente, no processo de aprendizagem e desenvolvimento das competências (GODOY; ANTONELLO, 2009).

Por fim, nota-se no grupo "muito satisfeitos" uma incidência maior de alunos que estavam realizando estágio na área, ao passo que os alunos que ainda não haviam estagiado na área foi menor. Tais resultados indicam que os programas de estágio facilitam o processo de aprendizagem ao oportunizarem a aplicação prática dos conteúdos teóricos, contribuindo para uma percepção mais positiva sobre o desenvolvimento das competências analisadas (GODOY; ANTONELLO, 2009; MURARI; HELAL, 2009).

A partir dos três agrupamentos realizou-se a análise discriminante por intermédio do método Stepwise (por etapas). Para Hair et al. (2009), bem como para Khattree e Naik (2000) esse método se caracteriza pela inserção das variáveis em passos distintos, chegando a constituir um modelo estatístico que discrimina e classifica o comportamento dos respondentes com relação à variável dependente.

A discriminação entre os grupos possibilitou a constatação de que o grupo 1 "menos satisfeitos" é formado por respondentes que atribuem médias mais baixas às variáveis discriminatórias, enquanto o grupo 3 "muito satisfeitos" tem médias mais elevadas, por fim, o grupo 2 "satisfeito" atribui médias que se colocam na intermediação dos demais grupos. Os resultados são apresentados na Tabela 3.

\begin{tabular}{lll|ll|lc} 
& \multicolumn{2}{l|}{ Menos satisfeitos } & \multicolumn{2}{l|}{ Satisfeitos } & \multicolumn{2}{l}{ Muito Satisfeitos } \\
\cline { 2 - 7 } & Média & $\begin{array}{c}\text { Desvio } \\
\text { padrão }\end{array}$ & Média & $\begin{array}{l}\text { Desvio } \\
\text { padrã } \\
\text { o }\end{array}$ & Média & $\begin{array}{c}\text { Desvio } \\
\text { padrão }\end{array}$ \\
\hline Aprender e aplicar novos conceitos e tecnologias & 6,01 & 1,66 & 7,65 & 1,26 & 8,85 & 0,82 \\
Trabalhar em equipe & 6,76 & 2,16 & 8,60 & 0,97 & 9,06 & 1,91 \\
Criatividade & 5,60 & 1,75 & 7,62 & 1,21 & 9,00 & 1,00 \\
Visão de mundo ampla e global & 6,86 & 1,79 & 7,85 & 1,19 & 9,54 & 0,55 \\
Comprometimento e responsabilidade & 7,80 & 1,93 & 8,66 & 1,25 & 9,53 & 0,69 \\
Comunicação e uso da linguagem escrita e falada & 6,77 & 1,85 & 8,08 & 1,23 & 9,57 & 0,47 \\
Capacidade de lidar com incertezas e dúvidas & 5,75 & 1,59 & 7,58 & 1,01 & 8,50 & 0,95 \\
Domínio de novos conhecimentos técnicos & 6,62 & 1,92 & 7,86 & 1,11 & 9,30 & 0,78 \\
Capacidade de inovação & 6,04 & 1,61 & 7,93 & 1,17 & 9,24 & 0,89 \\
Capacidade de relacionamento interpessoal & 7,11 & 1,44 & 8,35 & 1,25 & 9,44 & 0,65 \\
Iniciativa de ação e decisão & 6,34 & 1,65 & 8,12 & 1,14 & 9,52 & 0,68 \\
Capacidade de gerar resultados efetivos em grupo & 6,57 & 1,78 & 8,30 & 0,96 & 9,10 & 0,79 \\
Autocontrole emocional & 6,29 & 1,99 & 7,90 & 1,38 & 9,07 & 0,95 \\
Capacidade empreendedora & 5,46 & 2,09 & 8,07 & 1,05 & 9,30 & 0,72 \\
Lidar com situaçães novas e inusitadas & 6,02 & 1,88 & 8,03 & 1,03 & 9,09 & 0,88 \\
\hline
\end{tabular}




\begin{tabular}{llll|ll|ll}
\hline Índice de Competências Desenvolvidas - ICD & 6,40 & 1,81 & 8,04 & 1,15 & 9,21 & 0,85 \\
\hline
\end{tabular}

Tabela 3: Médias dos grupos extraídos pela análise discriminante

Fonte: Dados da pesquisa

Percebe-se uma separação no perfil dos respondentes, sendo possível identificar no grupo 1, formado pelos respondentes "menos satisfeitos", que o ICD foi de apenas 6,40, bem inferior ao índice das competências requeridas (7,80) identificado por Sant'Anna (2002). Percebe-se ainda, que a competência empreendedora representa a menor média entre as competências investigadas, enquanto a competência de comunicação e uso da linguagem escrita e falada representa a maior média. Reagrupando os grupos através do conjunto de competências descritas pela análise fatorial, a Tabela 4 apresenta os seguintes valores:

\begin{tabular}{ll|l|l}
\cline { 2 - 4 } & $\begin{array}{l}\text { Competências } \\
\text { interpessoais }\end{array}$ & $\begin{array}{l}\text { Competências } \\
\text { empreendedoras }\end{array}$ & $\begin{array}{l}\text { Competências } \\
\text { sistêmicas }\end{array}$ \\
\hline ICD (Mais insatisfeitos) & 6,51 & 5,89 & 6,86 \\
\hline ICD (Satisfeitos) & 8,21 & 7,81 & 8,06 \\
\hline ICD (Muito satisfeitos) & 9,21 & 9,07 & 9,37 \\
\hline
\end{tabular}

Tabela 4: Agrupamento das competências requeridas pela análise discriminante e análise fatorial Fonte: Dados da pesquisa

Os dados confirmam a hipótese de que o grupo das "competências empreendedoras" é o menos desenvolvido no ambiente acadêmico, independentemente dos agrupamentos pesquisados, chegando a atingir uma média de 5,89 para os pesquisados pertencentes ao grupo "menos satisfeitos".

Tais resultados indicam a necessidade de desenvolver competências empreendedoras e criativas no ambiente acadêmico, estimulando habilidades que permitam aos alunos lidarem com incertezas e dúvidas em processos contextualizados e reconhecidos através de trocas com o ambiente (RUAS; ANTONELLO; BOFF, 2005).

Por fim, com o propósito de analisar quais variáveis melhor discriminam os grupos analisados, foram identificadas 5 (cinco) competências significativas a 1\% pelo teste de Wilks' Lambda, são elas: "capacidade de aprender e aplicar novos conceitos e tecnologias"; "iniciativa de ação e decisão"; "visão de mundo ampla e global"; "capacidade de lidar com incertezas e dúvidas" e "capacidade empreendedora", conforme apresentadas na Tabela 5.

\begin{tabular}{ll|l|l}
\cline { 2 - 4 } & $\begin{array}{l}\text { Grupo 1 - Menos } \\
\text { satisfeitos }\end{array}$ & $\begin{array}{l}\text { Grupo 2 - Grupo 3 - Muito } \\
\text { Satisfeitos }\end{array}$ & $\begin{array}{l}\text { Satisfeitos } \\
\text { Satos }\end{array}$ \\
\hline Aprender e aplicar novos conceitos e tecnologias & 2,048 & 2,709 & 3,100 \\
\hline Iniciativa de ação e decisão & 3,260 & 3,619 & 4,450 \\
\hline Visão de mundo ampla e global & 3,229 & 4,268 & 4,752 \\
\hline Capacidade de lidar com incertezas e dúvidas & 3,014 & 3,756 & 4,439 \\
\hline Capacidade empreendedora & 2,177 & 3,349 & 3,839 \\
\hline Constante & $-43,281$ & $-70,150$ & $-95,867$ \\
\hline
\end{tabular}

Tabela 5: Coeficientes da função discriminante

Fonte: Dados da pesquisa

Níveis mais baixos no desenvolvimento destas competências tendem a classificar os respondentes no grupo 1 "Menos satisfeitos", pois afeta o desenvolvimento de outras 


\section{A FORMAÇÃO DO ADMINISTRADOR NA PERSPECTIVA DAS COMPETÊNCIAS INDIVIDUAIS REQUERIDAS}

competências.

Já níveis mais altos no desenvolvimento destas competências tendem a elevar o desenvolvimento de outras, melhorando assim o índice das competências desenvolvidas pelas instituições de ensino.

\section{Considerações finais}

A partir dos resultados apresentados é possível evidenciar que o conjunto de competências requeridas tem sido bem desenvolvido nas instituições de ensino pesquisadas, atingindo valores muito próximos do Índice de Competências Requeridas identificado por Sant'Anna (2002). No entanto, percebe-se que o conjunto de competências empreendedoras não tem sido desenvolvido na mesma proporção que o conjunto de outras competências. Considerando que a gestão de competências tem assumido perspectivas multiparadigmáticas cada vez mais mutáveis e complexas, a mobilização de competências empreendedoras torna-se essencial para estabelecer um quadro de competências adequado (RYCHEN; SALGANIK, 2005; FLEURY; FLEURY, 2001).

No entanto, para desenvolver melhor este grupo de competências, torna-se necessário estimular processos de aprendizagem que instiguem o pensar e o agir reflexivamente, envolvendo não apenas a capacidade de aplicar rotineiramente uma fórmula ou método para enfrentar uma situação, mas também a capacidade de lidar com as mudanças, aprender com a experiência e mobilizar conhecimentos que permitem agir através de uma postura crítica e criativa (RYCHEN; SALGANIK, 2005).

Complementar a estes resultados, as análises de cluster e discriminante permitiram uma investigação mais aprofundada sobre o desenvolvimento de competências no ambiente acadêmico, sendo identificado pelo subgrupo "menos satisfeitos", caracterizado pelo perfil jovem e inexperiente, um nível de desenvolvimento de competências bem inferior às "requeridas" pelo mercado, reforçando a necessidade de uma experimentação prática com o mercado de trabalho para o desenvolvimento de competências (COMINI et al., 2008). Uma prática viável para promover esta experimentação se refere aos programas de estágios, pois facilitam o processo de aprendizagem ao oportunizarem a aplicação prática dos conteúdos teóricos (GODOY; ANTONELLO, 2009; MURARI; HELAL, 2009).

Identificou-se, ainda, a necessidade de uma maior atenção às competências: "capacidade de aprender e aplicar novos conceitos e tecnologias"; "iniciativa de ação e decisão"; "visão de mundo ampla e global"; "capacidade de lidar com incertezas e dúvidas" e "capacidade empreendedora", pois estas apresentam maior impacto no desenvolvimento das demais competências requeridas, sendo as que melhor discriminam os grupos quanto ao nível de desenvolvimento das competências individuais requeridas no ambiente acadêmico.

Dentre as limitações do estudo, ressalta-se a necessidade de investigar outros cursos e instituições para avaliar se os resultados encontrados podem ser validados, assim como comparar se existem diferenças no desenvolvimento das competências individuais requeridas entre instituições públicas e privadas ou nas modalidades presencial e a distância, inferindo resultados para diferentes debates sobre um novo currículo por competências (CHIZZOTTI; CASALI, 2012; FLEURY; FLEURY, 2001).

Ademais, espera-se iniciar novos debates sobre a gestão de competências para além da 
abordagem tradicional (organizações), o que poderá ser útil para que as instituições de ensino avaliem e questionem os tradicionais modelos de currículos, considerando a formação de competências requeridas como algo que transcende a qualificação técnica, visando a outras habilidades psicossociais como necessárias a uma formação sistêmica dos indivíduos, tanto para sua inserção no mercado de trabalho como para sua formação cidadã.

\section{Referências}

BLAS, F. A. Competencias profesionales en la Formación Profesional. Madrid: Alianza, 2007. BOYATZIS, R. E. The competent manager: A model for effective performance. New York: John Wiley \& Sons, 1982.

CHIZZOTTI, A.; CASALI, A. O paradigma curricular europeu das competências. Cadernos de História da Educação, v. 11, n. 1, p. 13-30, 2012.

COMINI, G. M.; KONUMA, C. M.; SANTOS, A. L. Sistema de gestão de pessoas por competências: Um olhar crítico para a dimensão do desenvolvimento individual. Gestão \& Regionalidade, v. 24, n. 69, p. 6-18, 2008.

FÁVERO, L. P. et al. Análise de dados: modelagem multivariada para tomada de decisões. Rio de Janeiro: Elsevier, 2009.

FLEURY, M. T. L.; FLEURY, A. Construindo o Conceito de Competência. RAC, edição especial, p. 183-196, 2001.

GODOY, A. S.; ANTONELLO, C. S. Competências individuais adquiridas durante os anos de graduação de alunos do Curso de Administração de Empresas. Revista de Ciências da Administração, v. 11, n. 23, p. 157-191, 2009.

HAIR, F. Jr. et al. Análise Multivariada de Dados. Porto Alegre: Bookman, 2009.

KHATTREE, R.; NAIK, D. N. Multivariate data reduction and discrimination with SAS software. Cary, NC, USA: SAS Institute Inc, 2000.

LE BOTERF, G. De la compétence: essai sur un attracteur étrange. Paris: Editions d'Organizations, 1994.

LIMA, M. A. M.; ROCHA, B. P. L. Avaliação de Programas de Gestão por Competências: um estudo em organizações da Região Metropolitana de Fortaleza-CE. Organizações em contexto, v. 8, n. 16, p. 167-194, 2012.

MALHOTRA, N. K. Pesquisa de Marketing: Uma Orientação aplicada. Porto Alegre: Bookman, 2006.

MARTÍNEZ, F. M.; CARMONA, G. Aproximación al Concepto de "Competencias Emprendedoras": Valor Social e Implicaciones Educativas. Revista Iberoamericana sobre Calidad, Eficacia y Cambio en Educación, v. 7, n. 3, p. 82-98, 2009.

MCCLELLAND, D. C. Testing for Competence Rather Than for "Intelligence". American Psychologist, 1973. Disponível em < http:www.lichaoping.com/wp-content/ap7301001.pdf $>$ acesso em 15 de Maio de 2014.

MURARI, J. M. F.; HELAL, D. H. O estágio e a formação de competências profissionais em 


\section{A FORMAÇÃO DO ADMINISTRADOR NA PERSPECTIVA DAS COMPETÊNCIAS INDIVIDUAIS REQUERIDAS}

estudantes de administração. Gestão e Planejamento, v. 10, n. 2, p. 262-280, 2009.

OECD. Definition and Selection of Competencies: Theoretical and Conceptual Foundations (DeSeCo). Background Paper, 2001. Disponível em: <www.oecd.org/education/skills-beyondschool/41529556.pdf> $>$, acesso em 20 de Maio de 2014.

PERRENOUD, P. Ensinar: agir na urgência, decidir na incerteza. Porto Alegre: Artmed, 2001.

REJAS-MUSLERA, R.; URQUIZA, A.; CEPEDA, I. Competency-Based Model Through It: An Action Research Project. Systemic Practice and Action Research, v. 25, n. 2, 2011.

RUAS, R. L.; ANTONELLO, C. S.; BOFF, L. H. Os novos horizontes da gestão: aprendizagem organizacional e competências. Porto Alegre: Bookman, 2005.

RYCHEN, D. S.; SALGANIK, L. H. The definition and selection of key competencies: Executive summary. OECD, 2005. Disponível em: <www.oecd.org/pisa/35070367.pdf>, acesso em 15 de Maio de 2014.

SÁIZ, M. G. Una revisión constructiva de la gestión por competências. Anales de psicología, v. 27, n. 2, p. 473-497, 2011.

SANT'ANNA, A. S. Competências individuais requeridas, Modernidade organizacional e satisfação no trabalho: Uma análise de organizações mineiras sob a ótica de profissionais da área de administração. 2002. 366 p. Tese (Doutorado em Administração) - Universidade Federal de Minas Gerais, Belo Horizonte, 2002.

SANTOS, A. C. Gestão do conhecimento, da organização que aprende e de competências: a era digital. RAUSP, v. 38, n. 1, p. 77-83, 2003.

UBEDA, C. L.; SANTOS, F. C. A. Os principais desafios da gestão de competências humanas em um instituto público de pesquisa. Gestão e Produção, v. 15, n. 1, p. 189-199, 2008.

VERGARA, S. C. Métodos de Pesquisa em Administração. São Paulo: Atlas, 2006.

ZARIFIAN, P. 0 modelo da competência: trajetória histórica, desafios atuais e propostas. São Paulo: SENAC, 2003.

ZUAZO, L. A. Competencias fundamentales para la vida. Guatemala: Universidad Rafael Landivar, 2010. 